\title{
El patrimonio documental en la provincia de Cádiz: esperanzas y desafíos
}

\section{Antonio Rodríguez Cabañas}

Jefe del Servicio de Archivo y Publicaciones Diputación de Cádiz

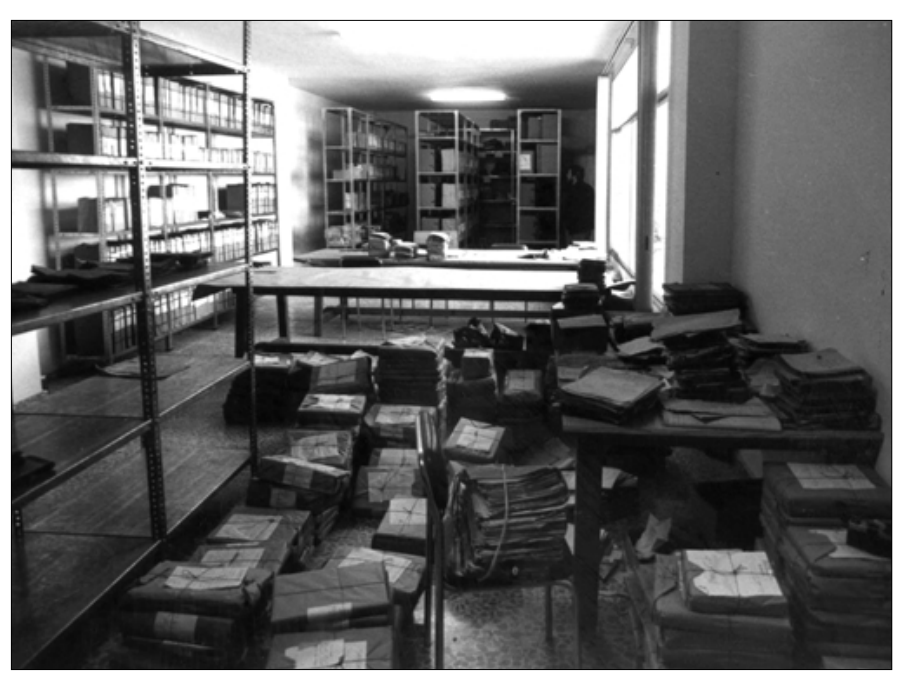

Resumen

Se analizan las esperanzas y desafíos que plantea la Sociedad del Conocimiento al promover una nueva valoración del Patrimonio Histórico. Éste ya no se entiende sólo desde una perspectiva pasiva (conjunto de bienes que es necesario preservar) sino que requiere nuevas posiciones activas al adquirir rentabilidad social, económica y cultural. Pasa a ser una auténtica fuente de riqueza de una región o un país, que sirve para elevar el nivel de conocimiento y formación de la sociedad.

Se evalúan las fuentes de información, especialmente las documentales de la provincia de Cádiz. Y se realiza una diagnosis sobre su estado actual, indicándose además direcciones y referencias de los dife- rentes recursos de información con el objeto de acercarlos a los investigadores y usuarios.

\section{Palabras clave}

Patrimonio histórico / Patrimonio documental / Sociedad del conocimiento / Fuentes de Información / Archivos / Bibliotecas / provincia de Cádiz

\section{Introducción}

EI PATRIMONIO, de acuerdo con lo que señala el avance del Segundo PLAN DE BIENES CULTURALES de Andalucía, podemos definirlo cono el conjunto de elementos naturales o culturales, materiales o inmateriales, heredados del pasado o creados en el presente, en donde un determinado grupo de individuos reconocen sus señas de identidad!

Sobre este Patrimonio es conveniente actuar ampliándolo, mejorándolo y utilizándolo con el objeto de obtener una rentabilidad social económica y cultural.

El Patrimonio no es sólo un conjunto de bienes que es necesario preservar o conservar, sino también una forma de entender la cultura, una determinada actitud social. Es una nueva manera de asumir los bienes culturales y el patrimonio como recursos que pueden y deben ser explotados social, económica y culturalmente. En este sentido, el Patrimonio pasa desde las concepciones o perspectivas pasivas a las activas, es decir, de ser recursos olvidados y abandonados, con el consiguiente deterioro que ello produce, a ser recursos, primero que deben ser como mínimo preservados, y en segundo lugar se conciben como auténticas fuentes de riqueza de un país o una región.

El ser fuente de riqueza hay que entenderlo no sólo desde el punto de vista mercantilista o exclusivamente comercial, sino que, si se potencia adecuadamente, puede ser fuente de enriquecimiento cultural de una sociedad. No sólo debemos hablar en términos de 
explotación dineraria sino sobre todo de un nuevo recurso, o del afloramiento de un recurso latente, que sirve para atender las nuevas demandas de ocio y cultura que las sociedades avanzadas y cultas exigen, y que los responsables directos del Patrimonio tienen que ofertar para ampliar y elevar el nivel educativo, cultural, y, como consecuencia de ello, también el social y económico de los ciudadanos.

\section{El patrimonio se convierte pues en un factor de desarrollo:}

La sociedad de este milenio -evidentemente estamos hablando del primer mundo, o a lo sumo de los países en fase de desarrollo-, que ya se prepara y muestra los signos de lo que será el inicio del futuro, presenta una serie de transformaciones que suponen un cambio profundo de la realidad social y económica hasta ahora dominantes.

Desde una sociedad basada en sus aspectos económicos en el desarrollo industrial, se ha ido pasando paulatinamente hacia otra en la que el sector terciario ha ido asumiendo cada vez más peso, produciéndose un paso hacia una economía de servicios en donde tiene cada vez más valor el llamado capital intangible.

La sociedad de más cercano futuro tiene nombre: es la denominada sociedad de la información y del conocimiento, en la que las nuevas Tecnologías de la Información se convierten en ejes centrales en el ciclo del desarrollo económico. Ello provoca una transformación radical en las formas sociales, afectando de forma esencial al mundo del trabajo, a las comunicaciones, y al desarrollo social y cultural; en consecuencia actúa sobre el modelo de sociedad, revolucionándolo.

En esta línea, recursos que hasta ahora no se habían tenido muy en cuenta alcanzan una valoración adecuada. Al elevarse el nivel educativo y cultural de los pueblos desarrollados y disponer de más tiempo y de más medios para el conocimiento y desarrollo intelectual, se produce un fenómeno de demanda y de descubrimiento de esos valores como son los intrínsecos al Patrimonio.

La existencia de un importante Patrimonio Cultural significa actualmente la presencia de una valiosa fuente de riqueza. Su puesta en valor de forma adecuada debe coadyuvar al progreso social y económico.

Del mismo modo, que las sociedades evolucionadas respetan y valoran cada vez más un Patrimonio Natural no degradado, y el Medio Ambiente se ha convertido en un factor de desarrollo sostenible, así el Patrimonio Cultural debe llegar a ser demandado como un hecho que debe ser conservado, acrecentado y difundido.

Por otra parte, el Patrimonio Cultural y el Patrimonio Natural suelen tener una progresiva confluencia. En Andalucía, con una gran riqueza y variedad tanto en uno como en otro, es necesario entenderlos de forma confluentes: ambos suelen ser el resultado de un sabio diálogo histórico entre las características físicas del territorio (Patrimonio Natural) y las culturas asentadas en él (Patrimonio Cultural).

Hasta no hace mucho el Patrimonio Histórico era un asunto de interés reducido a ciertas elites intelectuales y eruditos locales. Y el desarrollo era sinónimo de especulación, crecimiento descontrolado de las edificaciones urbanas en contraste con la cada vez mayor depresión rural.

Recientemente una serie de circunstancias han hecho cambiar el panorama del Patrimonio Histórico y su relación con el nuevo modelo de desarrollo que se impone:

- hay una mayor necesidad de bienes culturales por parte de la sociedad, sin duda movido por su mayor nivel económico y educativo, al estar cubiertas otras necesidades primarias. Es lo que se conoce como la práctica del ocio activo. 
- la globalización está provocando un fenómeno de movimientos de resistencia a la uniformidad que producen los monopolios y las grandes concentraciones empresariales.

- han sonado algunas alarmas que han provocado un replanteamiento del desarrollo desorbitado; poco a poco, y de forma excesivamente modesta, se impone un modelo más controlado y respetuoso con el medio, el conocido como desarrollo sostenible, que puede marcar unas nuevas pautas de actuación.

Las modas culturales y sociales vienen marcadas por las directrices de la "metrópoli del Imperio", que se propagan con suma facilidad a través de los medios de comunicación (la aldea global que señaló McLugham, o el actual movimiento denominado del "pensamiento único"). Esto ha provocado como reacción una oleada de contestación ante la uniformidad impuesta desde el exterior y se han empezado a reivindicar la recuperación de las tradiciones locales, los usos y costumbres transmitidos de padres a hijos, provocando un movimiento a favor de los valores asociados a la conservación del patrimonio en todos sus aspectos, como nueva manera de reivindicar las señas de identidad. Las redes informáticas (INTERNET), aparte de los efectos positivos que sin duda originarán sobre el desarrollo de las sociedades, pueden actuar, sin embargo, como auténtico Gran Hermano, que termine por imponer y vigilar todos nuestros movimientos.

Aunque todavía no se ha producido con respecto al Patrimonio un fenómeno semejante al provocado por la defensa del medio ambiente, que en muy poco tiempo se ha convertido en una bandera que ha calado fuertemente en toda la población, llegando incluso a ser todo lo "verde" una marca que funciona, se comercializa y se vende con facilidad, en definitiva, un nuevo recurso económico, es esperable que el Patrimonio Cultural, que podemos entenderlo entrelazado con el Patrimonio Natural, sea sentido y reivindicado por la población como un hecho relevante, y forma adecuada de desarrollo de la sociedad, acabando o reduciendo en gran parte los fuertes impactos que la acción desmesurada del hombre produce, con el consiguiente deterioro de la vida en nuestro al fin y al cabo limitado mundo.

En Andalucía, el Plan Económico Horizonte 2000 señala la importancia del sector servicios para la economía andaluza y especialmente los relacionados con el ocio y las actividades culturales, dada su creciente conexión con las actividades turísticas.

Por otra parte, el Plan Andaluz de Investigación, incluido en el Plan Económico, señalado antes, ha establecido dentro del área de Humanidades un subprograma de Ciencias y Tecnología del Patrimonio Histórico. La investigación en este campo se vertebra en una doble faceta:

I. Investigación científica, técnica y metodológica para la correcta protección y conservación del patrimonio.

2. Vinculación entre patrimonio y sociedad
Otros hechos en los que el papel dinamizador del Patrimonio es relevante, es en el fenómeno del desarroIlo rural, que viene de la mano del Turismo Rural. El antiguo Plan de Empleo Rural (PER), actual AEPSA, ya no es reivindicado sólo por los alcaldes para el arreglo de calles, alcantarillado, alumbrado, etc, sino que se pretende, y de hecho así se está produciendo, sea un instrumento para la recuperación y puesta en valor del Patrimonio.

Esta línea de actuación viene marcada también por las perspectivas analizadas y marcadas desde Bruselas. La Unión Europea, y así lo establecen los Programas FSE, FEDER, LEADER, ADAPT, y los concretos dedicados al Patrimonio RAPHAEL, CALEDOSCOPIO 2000, etc, van dirigidos a promover el desarrollo de las regiones más deprimidas, los primeros, y a desarrollar los hechos patrimoniales y culturales, los segundos. El libro Blanco de Delors ${ }^{2}$ ya apunta como un considerable yacimiento de empleo todo lo relacionado con el desarrollo del Patrimonio Cultural y marca la necesidad de que Europa sea sensible a la promoción de este Patrimonio como instrumento de desarrollo local y de la actividad ocupacional.

Ahí están las esperanzas y desafíos de un sector cada vez más en alza, pero que cuenta con importantes rémoras, que le vienen de una tradicional despreocupación por parte de los organismos responsables. En las páginas siguientes vamos a tratar de señalar el estado de la cuestión, fundamentalmente con el objetivo de presentar las fuentes documentales existentes en la provincia. Conocer nuestro patrimonio para poder protegerlo, utilizarlo y difundirlo. Aunque daremos un repaso general a los Archivos y las Bibliotecas, en este artículo nos centraremos en los Archivos y esencialmente en los de ámbito local de la provincia de Cádiz. Ocasiones habrá de recorrer otras fuentes de información e incluso aquí se señalarán algunos caminos que pueden ser transitados por investigadores e interesados.

\section{Las Instituciones de Patrimonio: Archivos y Bibliotecas}

Estas instituciones pueden definirse como servicios básicos en cualquier comunidad. El grado de desarrollo de una sociedad puede medirse incluso mediante el índice de lectura de una población, o la capacidad para asegurar el acceso a la lectura, o el estado de conservación, acceso e investigación del Patrimonio Documental en particular, o el Patrimonio Histórico en general. Es decir, a partir de una serie de variables (equipamientos, recursos, personal cualificado, cantidad de usuarios, servicios prestados, calidad del servicio) que establezcamos relativas a las Instituciones del Patrimonio (Archivos, Bibliotecas y Museos), podemos medir el grado de desarrollo social. En este sentido, tenemos que concluir que, aunque en Andalucía se ha avanzado bastante, nuestros índices no son acordes con el nivel de los ámbitos territoriales a los que pertenecemos. 
En Andalucía, las Bibliotecas se concentran en las provincias más pobladas y predominan en el ámbito de los núcleos urbanos. En el campo de los Archivos, podemos señalar que están distribuidos por toda la región, sin embargo, esto no quiere decir que se les puedan considerar como tales, ya que en su mayoría son almacenes en donde se amontonan papeles sin orden ni concierto y en un manifiesto estado de deterioro; salvando, en el caso de los archivos municipales, a provincias como Sevilla y Huelva, que han llevado a cabo un plan sistemático de organización y puesta en servicio de estos importantes órganos administrativos y fuentes documentales. Hay casos, como el de Cádiz en el que se inició un plan de organización pero que por distintos factores fue abandonado. Mientras que en las dos primeras provincias mencionadas con anterioridad se continuó dicho Plan, por estar más avanzado y con unos resultados ya tangibles, en Cádiz, la fragilidad del Plan sin un apoyo decisivo por parte de la Diputación, dio al traste con lo iniciado. Las consecuencias fueron que una importante inversión pública fue dilapidada por falta de continuidad, y a excepción de los archivos que introdujeron en sus plantillas a técnicos especializados, como fue el caso de Sanlúcar y Chiclana, en los restantes que fueron organizados, se tendrá que desandar los pasos andados o, seguramente, volver a empezar, e incluirlos dentro de un nuevo Plan, con lo que retrasará la ejecución del nuevo proyecto, no rentabilizándose el gasto realizado.

En cuanto al Sistema Bibliotecario, tenemos por una parte la Biblioteca Provincial, que es la cabecera del sistema a nivel provincial, y las Bibliotecas Municipales, que forman parte de la red de Bibliotecas y se encuentran incluidas en el Centro Coordinador de Bibliotecas, organismo que dependió durante bastante tiempo de las Diputaciones. La realidad provincial hace posible la presencia de importantes bibliotecas municipales, que están fuera del Centro Coordinador: como son el caso de la Biblioteca Municipal de Jerez ${ }^{3}$, con su ya consolidada red, la Biblioteca Municipal de Cádiz, la de El Puerto de Santa María, la de Algeciras. Luego existen algunas Bibliotecas de Organismos e Instituciones, unas públicas como son el caso de la Biblioteca Lobo de San Fernando, la Biblioteca del Real Observatorio4; existen otras bajo la tutela de entidades privadas, como la Biblioteca de Temas Gaditano; de titularidad religiosa como la Biblioteca del Seminario; Biblioteca como la de la Real Academia de Bellas Artes $^{5}$, la del Casino Gaditano o del Ateneo, la Biblioteca de la Facultad de Medicina ${ }^{6}$, la red de bibliotecas universitarias ${ }^{7}$, etc.

En 1993 se terminó el primer Plan de Bibliotecas que completó la creación de Bibliotecas Públicas Municipales en todos los municipios andaluces de más de 5.000 habitantes.

A partir de 1994, se desarrolla una serie de programas orientados a la mejora del servicio bibliotecario y al desarrollo de la red de Bibliotecas andaluzas. Para ello, se continuaron los programas de nuevas dotaciones bibliográficas, nuevos equipamientos y el programa de automatización de las Bibliotecas cabeceras de la red.
En el ámbito regional tenemos que destacar la Biblioteca de Andalucía con sede en Granada ${ }^{8}$. Conforme al Decreto 325/1984 de 18 de diciembre que regula las normas de funcionamiento del Depósito Legal, la Biblioteca de Andalucía viene registrando cuantas publicaciones se editan en nuestra región. Con el objeto de difundir dichas publicaciones la Biblioteca edita los "Boletines de Depósito Legal" con dos series:

\section{Monografías \\ 2. Publicaciones periódicas}

Desde 1991 se colabora con el Ministerio de Cultura en la realización del Catálogo Colectivo del Patrimonio Bibliográfico, con 10.400 unidades de registros bibliográficos, fundamentalmente referidos a Bibliotecas de Granada.

\section{Las Herramientas genéricas de medición del Patrimonio Documental: El Censo-guía de Archivos}

El ingente patrimonio documental español y su aquilatamiento ha sido una preocupación constante de todas aquellas personas que de un modo u otro tenían que ver con su custodia y puesta en servicio, en especial a partir de mediados del siglo XIX. Es desde ese momento cuando, la ciencia para unos y técnica para otros conocida como Archivística, comienza a sentar sus principios más sólidos, lo cual no quita que con anterioridad no existieran criterios o fundamentos en los que basar la práctica de la organización y la descripción de los documentos. En España, afortunadamente hemos tenido siempre una cierta preocupación ordenancista respecto de éstos y ahí están como antecedentes el Código de Las Siete Partidas - la creación del Archivo de la Corona de Aragón?. o el de Simancas en el siglo XVI, como reservorio documental de la Corona de Castilla.

Los archiveros, como responsables directos de los documentos, se han afanado por desentrañar esa masa de papeles que se han ido atesorando en los distintos tipos de archivos. Unas veces, la práctica archivística o los conocimientos imperantes recomendaba la catalogación de los documentos, y se obtuvo mucha información de muy pocos documentos. En cambio, el avance producido en la archivística en los últimos cuarenta años nos ha basculado hacia otros procedimientos a la hora de cumplir con la máxima del archivero, que no es otra que la de servir los documentos. Hoy ya en el siglo XXI nos atrevemos a hablar de tratamiento de la información, proceso que en tiempos no muy lejanos podía haber sido condenado como herético.

Los instrumentos de descripción han ido evolucionando, así como la escala de prioridades, y es comúnmente aceptado que para hacer un diagnóstico de la situación, que nos ayude a tener una primera visión de qué es lo que poseemos, debemos realizar 


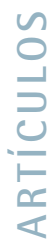

un Censo-Guía, medio básico para tener una panorámica de las fuentes documentales en distintos ámbitos territoriales, bien nacional o autonómico. Pero el Censo tendrá validez siempre y cuando esté actualizado y nos garantice calidad en la información que nos emite.

Actualmente, con los sistemas tecnológicos a nuestro alcance, ello es posible con cierta facilidad y comodidad, haciendo viable un alto nivel de difusión a un espectro de usuarios hasta hace muy poco tiempo impensable.

Esta herramienta debe estar, por tanto, bien engrasada y dentro de una maquinaria tecnológica con grandes potencialidades, puesto que si no es así y no la tenemos al día puede manifestar aún más las deficiencias y los fallos.

Los escasos medios que se dedican a este campo hace que tengamos que recurrir a instrumentos de descripción que abarquen un mayor número de ar-

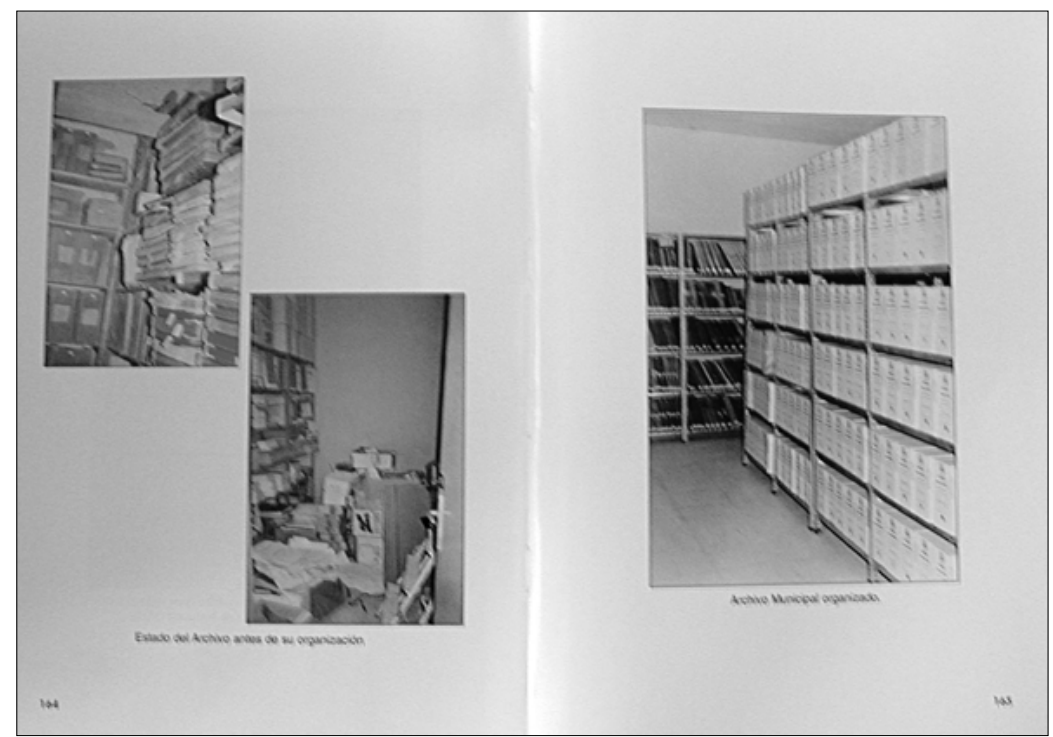

Estado del Archivo antes de su organización y Archivo Municipal una vez organizado chivos, aunque se transmita una menor profundidad en la información. El Censo-Guía pretende abarcar una amplia banda de tipos, sobre los que nos dará una mínima información. Pero es un primer paso y no por ello menos importante. También la Guía de Teléfonos nos da una información muy reducida sobre nuestras vidas, pero cuánta utilidad tiene!

Entre los años 1960 y 1970 y con la coordinación de la Inspección General de Archivos, a cuyo frente estaba Antonio Matilla Tascón, se realiza el CensoGuía de Archivos Españoles. Luis Sánchez Belda, siendo Director General de Archivos y Bibliotecas, señala en su prólogo 10 cuáles eran los tipos a los que se habían acudido: esencialmente "los archivos municipales y parroquiales, normalmente los menos conocidos y de más difícil acceso(...) Hemos excluido los archivos del Estado y, buena parte de los catedralicios y diocesanos por considerar que son más conocidos o que, al menos, cuentan con otros medios de información y, en general en ellos resulta más fácil el acceso." A pesar de las lagunas se optó por su publicación porque sin duda reportaría mucho beneficio a la investigación histórica.

La información que aporta este Censo es en primer lugar datos de localización del Archivo, y a continuación mención de las series contenidas, volumen y fechas extremas. Se entendía que con esos datos básicos se daban las pistas suficientes para que el historiador valorara si el fondo era de su interés o no. A falta de pan buenas son tortas, que diría el castizo. Sin duda, este instrumento es una toma del pulso de los archivos, y si se realiza de forma correcta da una información muy valiosa en primer lugar para la Administración de Archivos, que puede conocer y comprender la situación y valor de los fondos documentales y establecer a partir de ahí las líneas de actuación, y, en segundo lugar, a los usuarios se les aporta unos datos mínimos, pero en muchos casos esenciales, para encaminar o no una investigación o consulta hacia determinados fondos.

Pero además, y ya venía a bosquejarlo Sánchez Belda, el Censo cumple un papel importante como instrumento de tutela del Patrimonio Histórico. La publicación del Censo viene a representar un testimonio de lo que existe, siendo de esta forma un medio útil para proteger el Patrimonio Documental. Sería conveniente, en este sentido, realizar estudios comparativos de los distintos Censos o de las anteriores encuestas que se encargaban desde la Administración. Algunas pérdidas de documentos importantes saldrían a la luz y mostrarían de forma palpable cuál ha sido la preocupación de las instituciones propietarias de los fondos por su conservación o acrecentamiento"'.

En los últimos veinte años hemos avanzado bastante, aunque no todo lo que sería necesario, en la protección del Patrimonio Histórico en general y en particular en la organización de archivos, fundamentalmente en los de la Administraciones Públicas. Mejores locales, más presupuesto, más profesionales, dan como resultado una mayor conservación de los documentos y un mejor servicio, con lo que los ciudadanos salen beneficiados al poder acceder con mayor facilidad y comodidad a documentos que bien le atañen personalmente, puesto que están incluidos en expedientes administrativos que le afectan directamente, o bien al conocimiento de periodos y actividades pasados que pueden de algún modo tener una clara influencia en su devenir cotidiano.

La historia como materia de más amplio espectro, pero también la geografía, la política, el derecho, la medicina, la asistencia social, la protección del medio ambiente, la meteorología, la economía, la demografía, las mentalidades, la biografía, y quién sabe si la biotecnología o la genética, de tanta actualidad hoy, en fin, no pararíamos de relacionar facetas del conocimiento humano que se pueden ver favorecidas con unos archivos organizados y puestos en uso público. 
Un documento tiene un verso y un reverso, pero miles de lecturas. Los archiveros hemos podido comprobar como aquel documento, cuya capacidad de información se consideraba agotada, vuelve a obtener nuevas interpretaciones por los investigadores y usuarios, de tal forma que podemos afirmar que las modas y las tendencias en el campo de la historiografía han pasado una y otra vez sobre los mismos documentos.

A pesar de los avances que se han llevado a cabo, sólo tenemos que realizar una comparación entre distintas informaciones que nos aportan los Censos realizados, o las encuestas, sobre fondos documentales, para comprobar como el Patrimonio Documental se ha degradado por pérdidas, descuidos, expolios, ignorancia o falta de previsión.

Al repasar esa información de periodos anteriores se nos pueden poner los dientes largos, si no nos chirrían, ante la merma de importantes series documentales ${ }^{12}$.

En el primer Censo sólo se aportaron datos de los archivos municipales de Cádiz, Conil, Jerez, Jimena, San Roque, Tarifa y Vejer, que ahora nos pueden servir para estudiar la evolución de los fondos.

En el año 1983 y siendo Directora General de Archivos Margarita Vázquez de Parga, se planteó una revisión del Censo-Guía. Siguiendo las recomendaciones marcadas por la UNESCO y el Consejo Internacional de Archivos (CIA), se puso en marcha la realización de un nueva recopilación de datos sobre archivos y fondos documentales sin excepción ${ }^{13}$. En la provincia de Cádiz se contrataron por el Ministerio de Cultura a tres técnicos para que realizaran las pertinentes visitas a los archivos o centros en los que se considerara que tenían fondos documentales, que pudieran tener cierta relevancia. Esta recogida de datos, que daría lugar a la confección de un nuevo Censo-Guía más actualizado y con una mayor amplitud de archivos, se inició en nuestra provincia en 15 municipios, los del área de la Bahía, la Janda y el Bajo Guadalquivir. Quedaron fuera, por falta de presupuesto, los municipios de la Sierra y el Campo de Gibraltar. Durante cuatro meses se recogieron los datos pertinentes, de la mejor forma que los escasos medios otorgaban, a lo que había que añadir las dificultades que se encontraban en una falta de planificación, o las resistencias que se planteaban ante una realidad nefasta y desacostumbrada a tener cualquier tipo de interés.

La colaboración fue diversa y los obstáculos fueron suplidos por el entusiasmo y la dedicación de los encargados de recopilar los datos. Desde ser recibidos como si fueran inspectores de hacienda encubiertos al mayor desprecio o desgana, los prospectores de la información realizaron una labor paciente con la clara idea y objetivo de dibujar un panorama lo más cercano a la realidad del Patrimonio Documental. El reducido tiempo del que se contaba actuaba en contra de una mayor calidad de la información. En cualquier caso, la realidad superaba a cualquier ficción que pudiéramos imaginarnos, con lo que los

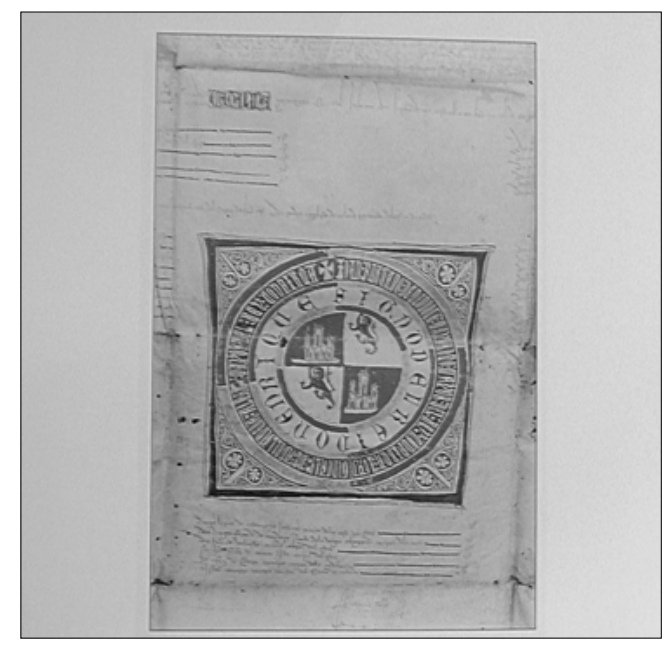

datos que se aportaban presentaban poca información en profundidad ante el estado generalizado de dejadez en el que se encontraban montones y montones de papeles abandonados a su suerte. Poca información en profundidad, pero mucha información general, que, en todo caso, aportaba un nuevo sondeo del estado de los fondos documentales.

Los objetivos marcados en el anterior Censo se repetían y podemos decir que poco se había realizado desde entonces. De nuevo tomábamos la temperatura a los archivos, a más archivos que antes y con mejores instrumentos, y los resultados daban que el enfermo continuaba con las mismas patologías y con la clara impresión de que habría que aplicarle, como mínimo, la respiración asistida.

Aquellas encuestas se realizaban sobre modelos recomendados por el CIA, y se incardinaban en el primer Plan de Informatización de Archivos que pretendía tratar toda esta vasta acumulación de información con las nuevas herramientas informáticas, que mejorarían sin duda la conservación y el acceso a los archivos y documentos. De este Plan sin duda el gran beneficiado fue el Archivo General de Indias (AGI), que, con el horizonte de la celebración del $V$ centenario del Descubrimiento en el año 1992, recibió una importante inversión. Pero también, esta atención sirvió para provocar fenómenos en cadena: Se desarrollaron planes provinciales de organización de archivos municipales, se promocionó la formación de archiveros -en Andalucía se crea por la Administración Autónoma y con la colaboración de la Universidad de Sevilla el primer curso de archiveros para postgraduados (1984), que luego se convirtió en el actual Máster de Archivística, y a ello se añadieron innumerables cursos y jornadas-, se empezó a legislar sobre la materia, siendo Andalucía la que marcara la pauta con la primera ley en España sobre Archivos en el año 1989. Podemos decir que en la década de los ochenta los archiveros y los archivos empiezan a salir de las catacumbas.

El Censo-Guía fue retomado por la Junta de Andalucía una vez realizadas las transferencias y en 1984- 1985 con una mayor duración en la recogida de datos se completó en aquella parte de la provincia en donde 
no se realizó durante la primera fase. Una vez completado el Censo se fue con posterioridad actualizando periódicamente, el resultado lo podemos comprobar en el Censo-Guía que dispone el Centro de Información Documental de Archivos (CIDA), dependiente de la Subdirección General de Archivos del Ministerio de Educación y Cultura. Este Censo está actualmente disponible en Internet, en la pagina del Ministerio de Educación y Cultura, en ella podemos acceder al Centro de Información Documental de Archivos (CIDA) y al Censo Guía de Archivos, Guía de Fuentes Documentales o Bibliografía de Archivos ${ }^{14}$.

Muy de pasada, puesto que la información con mayor amplitud podemos obtenerla en el sitio citado, realizaremos un ligero comentario sobre los datos que aporta el Censo para la provincia de Cádiz. Aparecen algo más de 400 registros. Debemos advertir que la información no está del todo actualizada con lo que pueden aparecen centros ya inexistentes o fondos que han sido transferidos al AHP, o direcciones que han cambiado ${ }^{15}$, o importantes fondos que faltan inexplicablemente. Por subsistemas de archivos podemos obtener la siguiente información:

- Archivo de la administración central: Órganos centrales del Estado. Aparece un archivo, el de Capitanía General de la Región Militar Sur (Sevilla), San Fernando. A este archivo se ha trasladado recientemente, con la oposición de importantes sectores de opinión, el archivo existente en el Gobierno Militar, que contenía entre otros el de la Junta Provincial de Fortificaciones.

- Archivos de la Administración Central: Órganos periféricos:

- Delegación provincial de Estadística (1904-1982)

- Delegación provincial de Abastecimiento y Transporte (1941-)

- Archivos Judiciales: aparecen registrados 7816

- Notariales y Registrales:

- Archivos de Prisiones: 4 (fechas límites 1936-)

- Centro Penitenciario de Preventivos de Cádiz (ya desaparecido)

- Centro Penitenciario de El Puerto de Santa María

- Centro Penitenciario de Cumplimiento de El Puerto de Santa María

- Archivos Militares:

- Archivo del Real Instituto y Observatorio de la Armada (San Fernando) ${ }^{17}$

- Archivo Histórico del Instituto Hidrográfico de la Marina 18

- Capitanía General de la Región Militar Sur Sevilla San Fernando (ya citado) ${ }^{19}$

-Archivos de la Administración Local:

- Archivo de Diputación

- Archivos Municipales

- Archivos Eclesiásticos:

- Parroquiales
- Monásticos 9

- Catedrales y Colegiatas

- Cofradías y Asociaciones Religiosas 7

- Hospitales:

- Centros Benéficos 7

- Entidades Bancarias 9

- de Empresas

- Partidos Políticos 3

- Sindicatos y Patronales 5

- Medios Comunicación 3

- Nobiliarios

- Personales y Familiares 2

- Centros Docentes 35

- Instituciones Científicas e Investigadoras 5

- Asociaciones 23

- Colegios profesionales I

- Asociaciones Culturales 4

- Recreativas y Deportivas 7

- ONGs

- Cámaras Agrarias 23

No podemos olvidar que en Archivos Nacionales (Histórico Nacional, General de la Administración, Simancas, General de Indias, etc.) podemos encontrar importantes fuentes documentales referidas a la provincia. Una buena puerta de entrada es la dirección de la página web ya citada cuando hablamos del Censo Guía de Archivos.

\section{El Censo Andaluz de Archivo}

Ya hemos señalado antes como en época más reciente se retomó la idea por parte del Ministerio de Cultura de realizar y actualizar los datos existentes sobre los distintos tipos de archivos con el fin primordial de poner esa información en los PICs (Puntos de Información Cultural), que cumplieron al principio una importante función pero que paradójicamente fueron eliminados sin que fueran sustituidos por nada. Afortunadamente, la aparición de Internet nos vuelve a ofrecer la posibilidad de disponer de esos y de mejores datos con mayor facilidad y comodidad. La tarea iniciada con el Ministerio fue completada por la Junta de Andalucía una vez transferidas las competencias correspondientes. En este sentido, se celebró un convenio con el Ministerio de Cultura en 1984 para introducir y actualizar los datos de los archivos andaluces en los PICs, como ya hemos señalado. Posteriormente, en 1985, la Consejería de Cultura puso en marcha el Censo de Archivos, un intento de completar la información existente y que en la recopilación de datos del Ministerio había sido incompleta al no abarcar todo el territorio. Este Censo se ha ido actualizando pero de 
una forma blanda o superficial. También en el año 1994 se planteó un Directorio de Archivos. Estos instrumentos de información tuvieron poca incidencia al no ser publicados y ser más bien herramientas de consumo interno, aunque, como ya he señalado, de escasa incidencia. En 1997, por fin se publica el Censo del Sistema Andaluz de Archivos 22 y como señala Antonia Heredia ${ }^{23}$ "es el instrumento de información más importante de entre los de su misma naturaleza, por básico, sintético y amplio. Su importancia nace de ser el vehículo obligado para el conocimiento global de los archivos dentro de una acotación territorial sin que, necesariamente, estén organizados, ni descritos, aunque éste debería ser el mejor punto de partida"24. Respecto a los anteriores, parte de un nuevo proyecto, aunque por supuesto comparte unos mismos objetivos y básicamente una misma estructura. La diferencia esencial, es que éste atiende sólo a los archivos del sistema andaluz, dejando fuera a sistemas importantes de archivos como son los estatales, eclesiásticos, privados... etc. Podemos afirmar que se ha realizado de forma concienzuda, con unos límites abarcables y publicado en un corto espacio de tiempo ${ }^{25}$, consiguiéndose que los resultados no fueran caducos antes de ver la luz, como es el caso, en parte, del Censo nacional, que por su falta de actualización nos ofrece unos datos que como mínimo debemos poner en cuarentena, dicho todo ello sin ánimo de restar otros valores que tiene. La presentación, en el XIV Congreso Internacional de Archivos celebrado en Sevilla los días del 21 al 26 de septiembre de 2000, de su versión en Internet -CÉNSARA ${ }^{26}$ - que permite un mejor acceso y una casi actualización en línea, lo cual le da a esta herramienta la verdadera potencialidad que debe tener en aras a un mejor servicio en relación a la tutela, la investigación, y, en resumen, el acceso a los magníficos bancos de datos que poco a poco se ponen a disposición de cada vez un mayor número de personas, y que son constitutivos de nuestro patrimonio documental. Una cuidada y ágil presentación de la información nos ofrece mayor credibilidad y es indicativo del inmenso trabajo que se encuentra detrás de este mundo cada vez más virtual.

Como complemento indispensable al Censo, se ha publicado BÍBARA, Bibliografía archivística andaluza, en la que se recoge toda la producción en este campo desde 1978. Este recurso de información de tanta utilidad se puede encontrar tanto en formato de libro como consultarse en la misma página web del Archivo General27. En ésta, sin duda, el acceso es más interactivo y versátil.

En este caso, a diferencia del Censo, que sólo es de los archivos del Sistema Andaluz, se vuelcan los registros bibliográficos sobre cualquier tipo de archivo del ámbito andaluz, con la limitación de las fechas que abarca (1978-2000), y se estructura en un capítulo dedicado a bibliografía institucional (legislación y censo); un capítulo para cada una de las provincias andaluzas con apartados referidos a tipos de archivos (estatales, universitarios, locales, eclesiásticos, privados); y un capítulo dedicado a bibliografía temática en donde se recogen aspectos tan diversos como Congresos, Jornadas, Manuales, Historia de la Archivística, Normalización, Fuentes Documentales, etc. Cierra el texto el correspondiente índice de autores y gráficos en donde se analizan la evolución de la producción bibliográfica. El resultado es la puesta a disposición de los usuarios de una manera sistematizada un número real de registros que asciende a 1297 títulos, que si cotejamos con los gráficos que se nos presentan al final, podemos comprobar que la evolución es positiva pues se pasa de 15 títulos publicados en 1978 a 87 en el año 1999. Ello nos da esperanzas y fuelle para seguir aportando un servicio digno a los ciudadanos, los cuales nos exigen cada vez más, como responsables directos de la gestión documental y del patrimonio, una calidad en la atención y en el acceso, que repercute en una mayor y mejor valoración de nuestro trabajo y de la materia prima sobre la que lo ejercemos: buenos recursos de información, base esencial para el desarrollo del conocimiento de la sociedad actual y venidera.

Y como no hay dos sin tres se ha publicado el Directorio de Archivo del Sistema Andaluz ${ }^{28}$, en donde se recogen la dirección y el responsable de cada archivo por provincia. Para nuestra provincia hay contabilizados 57 archivos: II autonómicos; 3 estatales, 43 de la administración local (no se han contemplado, por omisión u error, ni San José del Valle ni Setenil).

\section{Breve análisis de los Archivos de la provincia de Cádiz}

A principios de los años ochenta la situación archivística en la provincia de Cádiz se caracterizaba por una dejadez absoluta. Sólo podemos considerar que eran archivos en estricto sentido el Archivo Histórico Provincial (AHPC), creado oficialmente por el Decreto 746/1975, de 6 de marzo ${ }^{29}$, aunque tuviera antecedentes en el Archivo Histórico de Protocolos o en el de la Delegación de Hacienda; y en cuanto a los archivos de la administración local el de la Diputación provincial, aunque con una larga tradición de personal a cargo del archivo, prácticamente desde su instalación en septiembre de 1813 , no contaba en ese momento con un técnico de archivos; sí era el caso del Archivo Municipal de Cádiz, que, sin embargo, estaba en una situación deplorable. Otros archivos con personal cualificado eran el Archivo Municipal de El Puerto de Santa María; y el Municipal de Puerto Real, y algo después el de San Fernando. En el campo religioso ${ }^{30}$, en donde podemos encontrar fuentes de información muy relevantes y bastante utilizadas, están por una parte los parroquiales, custodiados por los respectivos párrocos. En líneas generales se encuentran bien conservados y al tener unas series documentales muy claras y controladas son archivos de los que se pueden obtener una alta rentabilidad investigadora. En el ámbito provincial, podemos encontrar a los diocesanos de Cádiz, por una parte, y el de Jerez, por otra. Éste último, ha venido aplicando la ins- 
trucción dada por la Conferencia episcopal ${ }^{31}$ para la concentración en instalaciones apropiadas y bajo la custodia y servicio de un archivero eclesiástico de los fondos de los archivos parroquiales de la diócesis con una antigüedad mayor al año 1900.

En cuanto a los privados, tenemos en nuestra provincia a uno de los más importantes archivos nobiliarios de España: el Archivo Ducal de Medina Sidonia32.

La Comunidad Autónoma de Andalucía recibe las transferencias de competencias en materias de cultura por diversas normas 33 y los archivos empiezan a tener mayor atención, aunque no toda la deseable. En Cádiz, la Diputación provincial aprueba en el año 1984 el Plan de Archivos Municipales (POAM) y establece una programación para que en el año 1992 estén todos los archivos municipales organizados. Por cambios en los intereses políticos, reducción de presupuestos, y con el argumento erróneo de lo que ordenaba la Ley conocida como de Diputacio$n^{3} s^{34}$, en la que se establecía un marco de relaciones y de separación de ámbitos de actuación entre la Junta de Andalucía y las Diputaciones, se consideró que el patrimonio documental era competencia de la Junta. Sin embargo, en Diputaciones como la de Sevilla y la de Huelva en las que se había apostado fuertemente por la recuperación del patrimonio documental local y por la puesta en servicio de los archivos municipales, se ampararon en aquel apartado de la Ley en que mencionaba que las Diputaciones atenderían a los municipios pequeños sobre todo los de menos de veinte mil habitantes. Su interpretación resultaba válida y lógica de acuerdo con lo que marcaba la Ley de Bases de Régimen Local35 como funciones y competencias que deben ejercer las Diputaciones provinciales. Lo cierto es que la ley de Diputaciones facilitó el que algunos responsables políticos, con cortedad de vista e intereses puestos en la política de cascabel y de fuegos artificiales, echaran por tierra lo poco que se había avanzado, dilapidando esfuerzos y recursos a mucha costa conseguidos.

De 1985 a 1989 que duró el primer POAM en Cádiz se organizaron los archivos municipales de Alcalá de los Gazules, Algar, Benaocaz, Chiclana, Chipiona y Medina Sidonia. No se concluyeron otros archivos en los que se inició la organización como fueron los casos de Rota, Sanlúcar, Torrealháquime, Trebujena, Vejer. Suspendido el POAM en 1989, se paralizó desde la administración provincial una importante labor de recuperación y puesta en servicio de los fondos documentales locales, y toda la planificación realizada se vino abajo por las causas ya apuntadas arriba. En 1996, con una nueva Corporación en la Diputación, se planteó desde su Archivo retomar el POAM; afortunadamente podemos decir que de nuevo estamos en el camino, largo y sinuoso, de organizar los archivos locales de nuestra provincia. Los resultados ya se dejan notar en tan poco tiempo, puesto que se han finalizado archivos que quedaron sin terminar y se han organizado otros nuevos, además los inventarios se han publicado con lo que podemos disponer de la rigurosa información que sobre el fondo y las series documentales que componen el archivo organizado y descrito nos aporta los inventarios o los instrumentos de descripción realizados.

Como centros públicos con fuentes de información más relevantes daremos un repaso al Archivo Histórico Provincial y al estado de los archivos de administración local en la provincia. Fuera quedarán para otra ocasión los eclesiásticos y los privados, que cuentan con importantes fuentes de información, pero que merecen mayor atención que la que aquí le podemos dedicar.

Desde la Junta de Andalucía se debería realizar una campaña de adecuación de la información y de actualización continua, de estos otros archivos, tal como se ha hecho con los archivos perteneciente al Sistema Andaluz.

\section{El Archivo Histórico Provincial}

Sin lugar a dudas, el AHPC es el archivo de mayor relevancia en el ámbito gaditano por la importancia y diversidad de sus fondos. Contiene como núcleo central los Archivos de los Registros Públicos, en el que destaca el Archivo de Protocolos, con documentos notariales de prácticamente toda la provincia. Quedan por incorporar dos fondos importantes como son los de Jerez y Algeciras, por la resistencia, en parte absurda, de los responsables locales, que no tienen reparo en negarse a estas transferencias en aras de una defensa de hechos diferenciales, dentro de una singular provincia en que estos recelos localistas o comarcales están a flor de piel; y no tienen reparos en tener completamente abandonados, en una situación que roza la ilegalidad, los fondos realmente de su propia competencia. Los distintos distritos notariales abarcan fechas límites que se inician en el siglo XVI y llegan hasta la actualidad, con los 100 años de restricción de acceso que tiene este tipo de documentos. Hay pérdidas muy reseñables como la del distrito de Sanlúcar, con Trebujena y Chipiona, que se perdió junto con parte del municipal en los sucesos de enero del año 1933, en que fue incendiado. Del valor de esa documentación podemos hacernos una idea por la importancia que ha tenido Sanlúcar desde el descubrimiento de América. Otro archivo de distrito también incendiado por motivos de orden público en 1936 fue el de Grazalema. Este archivo incorporaba información relativa a Benaocaz, Ubrique y Villaluenga, las cuatro villas hermanas, y que jugaron un papel importante y relevante en la historia provincial. El expolio de este patrimonio, al que suele ir parejo el municipal por estar en su mayoría ubicados en un mismo edificio, y por motivos plenamente irracionales, han mermado la riqueza de la información que hoy podríamos tener sobre esos lugares, perdiéndose significativos testimonios y señas de identidad. Tendrá que ser por otras vías por las que podamos recuperar en parte información relativa a estos lugares, acudiendo a los archivos nacionales o a los privados, en aquellos casos en los que estos municipios pertenecieran a algún señorío. Este camino, 
de todas formas, debe ser recorrido para realizar cualquier investigación o recuperación de información, pues es sabido que en un único archivo no localizaremos todos los datos que podamos necesitar.

Otros fondos son los de la Administración Periférica del Estado con documentos de Agricultura, Comercio, Cultura, Educación, Hacienda, Industria, Información y Turismo, Interior, Obras públicas, Presidencia, Sanidad, y Vivienda, con fechas límites mayoritariamente de los siglos $X I X$ y $X X$, aunque hay algunas secciones del XVIII o del XVI como es el caso de la Junta Provincial de Beneficencia, cuya documentación se comparte con la existente en el Archivo de la Diputación provincial.

La Administración Periférica de la Junta de Andalucía contiene los fondos de las Delegaciones creadas a raíz de la constitución de la Comunidad Autónoma, por lo que su información es relativamente reciente, aunque ha podido recoger algún antecedente previo.

La Administración Institucional del Estado contiene documentos como los de la Organización Sindical, la Comisaría de Abastecimientos y Transportes, el Instituto de Conservación de la Naturaleza (ICONA), el Instituto de Reforma y Desarrollo Agrario (IRYDA), etc, todos de este siglo. Y la Administración Institucional de la Junta de Andalucía en parte heredera de los anteriores: Instituto de Reforma Agraria (IARA) o el Servicio Andaluz de Salud (SAS).

Otro fondo es el de Instituciones del Movimiento Nacional con la Jefatura Provincial del Movimiento, la Sección Femenina o La Voz del Sur.

Por otra parte, la Administración Corporativa reúne fondos como la interesante documentación de los Colegios Profesionales; es el caso del de Arquitectos, o las Cámaras de propiedad urbana.

Todo esto en cuanto a los archivos públicos, respecto a los privados se encuentran fondos y colecciones de asociaciones y fundaciones, empresas, archivos religiosos, con documentos desde finales del siglo XVI. Por último posee una sección de documentos figurativos con mapas y planos de los siglos XVIII-XX y fotografías desde los años sesenta de este siglo.

Faltan muchos fondos por integrarse, pero si queremos conocer la realidad pasada de la provincia tenemos que acudir a este gran contenedor de datos, verdadera memoria provincial que es el AHP, mejorado sensiblemente en sus nuevas instalaciones de la Casa de las Cadenas, una vez fue trasladado en 1987 desde la planta baja del Palacio de la Aduana, sede de la Diputación provincial. Sus instalaciones adecuadas y la profesionalidad de su personal cubren con creces las deficiencias o la escasez propias de este tipo de instituciones. La Guía del Archivo ${ }^{36}$ es una primera puerta que debemos traspasar para hacernos una idea de la globalidad de sus fondos, pero otros instrumentos de descripción (inventarios, catálogos, índices), por supuesto desiguales dependiendo de los archivos, nos esperan para darnos más detalle o centrarnos más sobre nuestro objeto de búsqueda. Una búsqueda que puede ser muy intensa en sus más de 65000 unidades de instalación ente libros y cajas.

\section{Los archivos de titularidad autonómica}

Dentro de los archivos de titularidad autonómica están el de la Delegación provincial de Economía y Hacienda y el de la Delegación provincial de Obras Públicas y Transportes. Además están conceptuados como depósitos -es decir, no consiguen la categoría de archivo con todas sus consecuencias- los de las restantes Delegaciones de la Junta de Andalucía (Agricultura y Pesca; Cultura; Educación; Gobernación; Medio Ambiente; Salud; Trabajo e Industria; Turismo y Deporte) siempre referido a la fecha de recogida de datos. Se pueden producir variantes, bien por transferencias de documentos al AHPC, bien por traslado del archivero, bien por modificación de la estructura de la Junta de Andalucía, como es el caso de no contemplarse en ésta la presencia de la Delegación de Justicia, creada en la última remodelación gubernamental. En cualquier caso, en la página de Internet, ya señalada, en donde se recoge CÉNSARA, la información puede estar más actualizada.

El Archivo de la Delegación de Economía y Hacienda tiene 346 m con 14.852 unidades de instalación, y fechas extremas de 1975 a 1999. Dispone de un Inventario mecanografiado.

El Archivo de la Delegación de Obras Públicas y Transportes tiene $1.127 \mathrm{ml}$. con 7831 unidades de instalación, y fechas extremas de 1946 a 1994. Dispone de Inventarios.

Las demás Delegaciones disponen de depósitos de archivo en vez de archivo propiamente dicho, para seguir la terminología empleada en el Censo. Disponen de un total de $34.44,3$ metros lineales $(m)$ y las

\section{Archivos de la Administración Autonómica}

\begin{tabular}{lcccc}
\hline Nombre & $\begin{array}{c}\text { Fechas } \\
\text { extremas }\end{array}$ & $\begin{array}{c}\text { Unidades } \\
\text { de instalación }\end{array}$ & $\begin{array}{c}\text { Metros } \\
\text { lineales }\end{array}$ & $\begin{array}{c}\text { Instrumentos } \\
\text { de descripción }\end{array}$ \\
\hline Archivo Economía yHacienda & $1966-19951$ & 4852 & 346 & Inventario \\
\hline Archivo Obras Públicas y Transporte & $1946 / 1994$ & 7831 & 1127 & Inventario \\
\hline Depósito Agricultura y Pesca & $1988-1994$ & 1200 & 100 & \\
\hline Depósito Cultura & $1976-1995$ & 1453 & 202 & \\
\hline Depósito Educación & \multirow{2}{*}{ ? } & 2250 & 335 & Índices \\
\hline Depósito Gobernación & $1962-1996$ & 3601 & 442,9 & \\
\hline Depósito Medio Ambiente & $1983-1995$ & 2975 & 150 & \\
\hline Depósito Salud & $1972-1995$ & 5960 & 641 & Inventario \\
\hline Depósito Empleo y Desarrollo Tecnológico & $1940-1996$ & 11715 & 1520 & Inventario \\
\hline Depósito Turismo y Deporte & $1996-1995$ & 638 & 53,4 & Inventario \\
\hline Total & & 52475 & 4917,3 & \\
\hline
\end{tabular}

Fuente Censo del Sistema Andaluz de Archivos. Año 1997 y revisión de 1999 en Cénsara 
fechas extremas vendrían en algún caso desde los años cuarenta, siendo lo general desde los años sesenta. Debemos tener en cuenta que mucha de la documentación de estas Delegaciones puede encontrarse en el AHPC, por lo que es necesario cotejar entre los distintos fondos la información que nos interese localizar.

El personal técnico brilla por su ausencia. En todas estas Delegaciones de la Junta de Andalucía sólo existe un Ayudante de Archivos (Obras Públicas) y dos auxiliares administrativos. Todo el peso se descargará entonces sobre el AHPC, en donde con tres facultativos de archivos deben controlar toda esta masa de documentos incontrolados, al funcionar como archivo intermedio de la administración e histórico.

Se menciona también en el Censo la Biblioteca Pública provincial con un fondo con antigüedad desde 1847, 16 unidades de instalación y $4 \mathrm{~m}$; a lo que se añade el fondo del Depósito Legal con fechas extremas de 1958 a 1996 y 4 m; y el de el Museo Provincial con fechas extremas de 1990-1996, 67 unidades de instalación y $7 \mathrm{~m}$.

\section{Los archivos de la administración local}

En los archivos de la administración local podemos encontrar una parte muy importante de todo el devenir de la vida local. Son fuentes esenciales para el conocimiento del transcurso de la vida municipal, y que en muchos casos puede llegar a trascender esa escala reducida pero importante y servirnos para el conocimiento de sucesos de importancia nacional o internacional. No vamos a entrar en el análisis pormenorizado de cada uno de los archivos locales de la provincia, dibujaremos aquí un breve bosquejo a grandes trazos de la situación actual, incorporando

\subsubsection{Archivos con personal técnico}

\begin{tabular}{|c|c|c|c|c|}
\hline Nombre & $\begin{array}{c}\text { Fechas } \\
\text { extremas }\end{array}$ & $\begin{array}{l}\text { Unidades de } \\
\text { instalación }\end{array}$ & $\begin{array}{l}\text { Metros } \\
\text { lineales }\end{array}$ & $\begin{array}{l}\text { Instrumentos } \\
\text { de descripciór }\end{array}$ \\
\hline Diputación & $1494 / 1997$ & 10.741 & 987 & $\begin{array}{l}\text { Inventarios y } \\
\text { Catálogos } 38\end{array}$ \\
\hline Arcos & $1256 / 1996$ & 1.364 & 240 & Inventario \\
\hline Cádiz & $1263 / 1996$ & 28.802 & 2.600 & Inventario 39 \\
\hline Los Barrios & $1836 / 1994$ & ¿? & 400 & Inventario \\
\hline Chiclana & 1551-1984 & 2.737 & 1.000 & Inventario 40 \\
\hline Jerez & S.XII/1980 & 11.424 & 2.700 & Inventario 4 I \\
\hline El Puerto de Santa María & $1264 / 1988$ & 15.804 & 2.648 & Inventario 42 \\
\hline Puerto Real & $1547-1991$ & 5.887 & 841 & Inventario 43 \\
\hline Rota & $1806 / 1998$ & 8.000 & 840 & Inventario \\
\hline San Fernando & $1677 / 1995$ & 10.932 & 1.281 & Inventario 44 \\
\hline Sanlúcar & 1511-1995 & 9.417 & 645 & Inventario 45 \\
\hline San Roque & $1502-1990$ & 4.500 & 579 & Inventario \\
\hline Tarifa 46 & & & 532 & \\
\hline Vejer 47 & 1872/1996 & & 190 & \\
\hline Total & & 109.608 & 15.483 & \\
\hline
\end{tabular}

Elaboración propia a partir del Censo del Sistema Andaluz de archivos datos básicos como son si están o no organizados, si disponen de instrumentos de descripción y cuáles son, y las fechas extremas de la documentación de sus fondos con el volumen medido en metros lineales para que podamos hacernos una primera idea de en que situación se encuentran.

Podemos añadir además que en líneas generales los tipos de documentos que nos vamos a encontrar, en una gran diversidad de situaciones, son los que han sido generados o recibidos por la administración en el desarrollo de sus funciones, y que podemos agrupar en 4 grandes áreas: Gobierno, Administración, Servicios y Hacienda ${ }^{37}$. En la primera área podemos encontrar la documentación en la que se refleja las decisiones gubernativas locales, y las recibidas de otras administraciones, aquí se localizaron series tan importantes como las actas de gobierno. En el área de Administración, todas aquellas series referidas a la organización y funcionamiento de la institución (secretaría, correspondencia, registro, expedientes personales, contratación, servicios jurídicos, archivo). En el área de Servicios todas aquellas referidas al desempeño de competencias y funciones que realiza la institución y que tienen una influencia clara en la actividad local (Obras y urbanismo, abastos, consumo, seguridad ciudadana, sanidad, beneficencia, educación, cultura, deportes, población, quintas, elecciones). Por último, el área referida al funcionamiento económico (Presupuestos, recaudación, tributos, impuestos, tesorería).

La situación en cada corporación varía por muchos factores; podemos, en todo caso, establecer una primera clasificación en cuanto al estado de organización del archivo, de tal forma que podamos establecer un nivel de acceso a las fuentes en función de si tiene personal técnico o no y si ha sido organizado o no. A continuación en tres cuadros diferentes señalaremos a grandes rasgos estas distintas situaciones.

\section{Archivos con personal técnico}

Estos 13 municipios, más la Diputación provincial, son los que afortunadamente, y salvando las diferencias entre las distintas situaciones profesionales que se dan, han mostrado un rigor a la hora de contemplar en sus plantillas a técnicos que son garantes de un rico tesoro patrimonial. Sus actuaciones hacen posible la conservación y tutela de un importante volumen de documentos históricos que configuran las señas de identidad de esta provincia. Y, sobre todo, la existencia de servicios administrativos ágiles y eficaces, que permiten no sólo a los investigadores, sino sobre todo a los administradores y a los ciudadanos acceder a documentos organizados que sirven para la toma de decisiones y para la defensa de los derechos individuales y colectivos, y para la promoción y desarrollo del conocimiento y la cultura.

Archivos bajo supervisión del Plan de Archivos Municipales (POAM) 1985-2000. (Ver tabla) 
Depósitos de Archivos. Sin personal técnico y sin supervisión del POAM (1985-2000). (Ver tabla)

Estos 20 municipios son los que se encuentran en peores circunstancias en cuanto al estado de sus archivos municipales. Con casos flagrantes como el de Algeciras que con una población de más de 100.000 habitantes no cuenta en su plantilla con ningún personal responsable del archivo.

\section{Conclusiones}

Aunque es un tópico, o dicho común muy extendido, el Patrimonio Histórico, y sobre todo el Patrimonio Documental, es la cenicienta de la política educativa y cultural, ya que los responsables políticos sienten escaso aprecio por su conservación y tutela. Sólo cuando lleguemos a comprender los valores que aporta a la sociedad un Patrimonio rico y cuidado podremos sentirnos que pertenecemos a un mundo culturalmente sano y avanzado. Pero para ello, sin duda se debe dar paso a valorar la construcción de infraestructuras culturales frente a las actuaciones efímeras, muy costosas éstas en general y con dudoso rendimiento.

Pero no vamos a ser pesimistas, en estos últimos años se ha avanzado bastante en la tutela y puesta en valor del Patrimonio Histórico. Pero este avance conseguido fundamentalmente a base de mucho esfuerzo de convencimiento por parte de los profesionales hacia los responsables políticos, se encuentra en un estado que podríamos denominar de difícil equilibrio, puesto que no existe una apuesta decidida y sin complejos por la salvaguarda y uso de nuestro rico patrimonio documental. Tristes subvenciones por parte de la Comunidad Autónoma, escasa participación de la provincial y desidia por parte de la local, dibujan un panorama nada halagüeño. Por otra parte, no existe una clara racionalidad ni coherencia a la hora de abordar de una vez por todas esta cuestión. Con una actuación cooperativa por parte de todas las administraciones responsables -algo que los profesionales están aburridos de pregonar-y con una inversión nada excesiva, se podría solucionar este problema, consiguiéndose unos altos beneficios. Lo peor es la política del sí pero no, y no abordar con seriedad el dotar a la provincia en este caso de unas buenas infraestructuras culturales, que todo no tiene que reducirse a carreteras y ferrocarriles.

Si contemplamos el mapa de la provincia en relación a los archivos municipales, vemos que la mayor parte del territorio provincial o tiene técnicos -esencial para el funcionamiento de los archivos- o están de alguna manera bajo la supervisión del Plan de Archivos Municipales. Sólo los archivos de la Sierra se encuentran en peor posición. En la Janda y en el Campo de Gibraltar, con la grave excepción ya mencionada de Algeciras, pueden solventarse a medio plazo las carencias actuales.

Pero para que las intervenciones sean rentables se debe aprender de los errores anteriores. Si organizamos un archivo y entregamos la llave al responsable político al cabo del tiempo -no habrá que esperar mucho-

\begin{tabular}{|c|c|c|c|c|}
\hline \multicolumn{5}{|c|}{$\begin{array}{l}\text { Archivos bajo supervisión del Plan de Archivos Municipales (POAM) } 1985 \\
2000\end{array}$} \\
\hline Nombre & $\begin{array}{l}\text { Fechas } \\
\text { extremas }\end{array}$ & $\begin{array}{l}\text { Unidades } \\
\text { de instalación }\end{array}$ & $\begin{array}{l}\text { Metros } \\
\text { lineales }\end{array}$ & $\begin{array}{l}\text { Instrumentos de } \\
\text { descripción }\end{array}$ \\
\hline Alcalá de los Gazules & 1390/1990 & 2.279 & 250 & Inventario 48 \\
\hline Algar & 1766/1996 & 200 & 60 & Inventario \\
\hline Benalup-Casas Viejas & 1991-1997 & 1.000 & 125 & Inventario \\
\hline Benaocaz & 1579/1996 & 117 & 55 & Inventario \\
\hline Bornos & $1692 / 1995$ & 800 & & Inventario 49 \\
\hline Chipiona & $1611 / 1980$ & 1.363 & 210 & Inventario 50 \\
\hline Espera & $1527 / 1990$ & 894 & 310 & Inventario 51 \\
\hline Medina Sidonia & $1268 / 1996$ & 1.816 & 512 & Inventario 52 \\
\hline Trebujena & 1516/1996 & 799 & 125 & Inventario \\
\hline Ubrique & $1743 / 1991$ & 1.749 & 258 & Inventario 53 \\
\hline Villamartín 54 & $1556 / 1996$ & & 270 & \\
\hline Total & & 11.017 & 2.175 & \\
\hline
\end{tabular}

Elaboración propia a partir del Censo del Sistema Andaluz y de los instrumentos de descripción

Depósitos de Archivos. Sin personal técnico y sin supervisión del POAM (1985-2000)

\begin{tabular}{|c|c|c|c|c|}
\hline Nombre & $\begin{array}{l}\text { Fechas } \\
\text { extremas }\end{array}$ & $\begin{array}{l}\text { Unidades de } \\
\text { instalación }\end{array}$ & $\begin{array}{l}\text { Metros } \\
\text { lineales }\end{array}$ & $\begin{array}{l}\text { Instrumentos de } \\
\text { descripción }\end{array}$ \\
\hline Alcalá del Valle & $1903 / 1996$ & & 112 & \\
\hline Algeciras & $1557 / 1995^{55}$ & & 155 & \\
\hline Algodonales & $1900 / 1996$ & & 210 & \\
\hline Barbate & $1938 / 1996$ & & 50 & \\
\hline El Bosque & $1812-1996$ & 284 & 75 & \\
\hline Castellar & $1549 / 1996$ & & 150 & Inventario \\
\hline Conil & $1628 / 1986$ & & 50 & \\
\hline El Gastor & 1936/1996 & 290 & 63 & \\
\hline Grazalema & $1936-1996$ & & 106 & \\
\hline Jimena & $1815 / 1996$ & & 170 & Inventario 56 \\
\hline La Línea de la Concepción 57 & $1870 / 1979$ & 181 & & \\
\hline Olvera & $1645 / 1996$ & & 81 & \\
\hline Paterna de Rivera & $1660 / 1995$ & & 85 & \\
\hline Prado del Rey & 1934-1996 & & 167 & \\
\hline Puerto Serrano & $1820 / 1996$ & & 68 & \\
\hline \multicolumn{5}{|l|}{ San José del Valle } \\
\hline \multicolumn{5}{|l|}{ Setenil } \\
\hline Torre-Alháquime & $1640 / 1996$ & & 77 & \\
\hline Villaluenga del Rosario & $1936-1996$ & & 119 & \\
\hline Zahara de la Sierra & $1510 / 1996$ & & 85 & \\
\hline
\end{tabular}

Censo Andaluz de Archivos

\section{El sistema de archivos de administración local en la provincia de Cádiz}

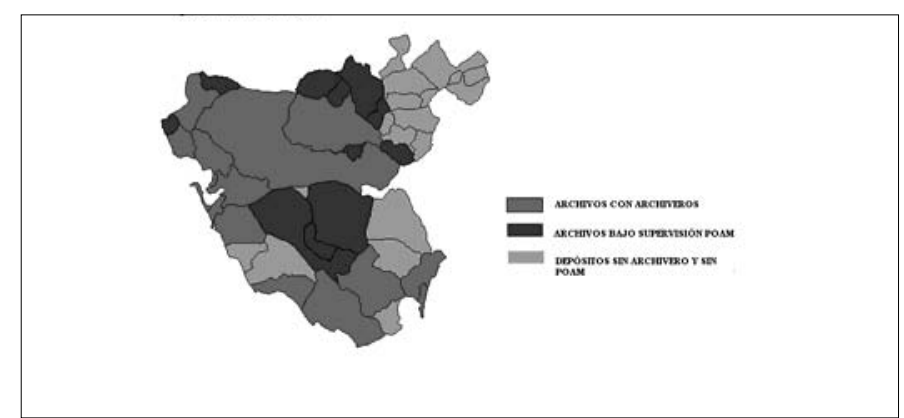


volveremos a la situación de desamparo anterior. Se deben dotar plazas de técnicos, que son los que podrán mantener el servicio organizado y darle rentabilidad al laborioso trabajo realizado, que no es otro que el uso de esas importantes fuentes documentales por los investigadores, usuarios e interesados en general. Se requiere por tanto establecer una estructura estable y consolidada que propicie la fácil recuperación de la información existente en los ricos fondos documentales de la provincia, y su difusión. Esto permitirá en unión de otros valores del Patrimonio provincial ren- tabilizar económica y culturalmente recursos que en muchos casos están dormidos.

Actualmente existen medios y sensibilidades para llevar a cabo sin excesivo coste una puesta en valor de los recursos patrimoniales existentes. Una buena conservación y tutela hará que no perdamos esos valores culturales y podamos atender la cada vez mayor demanda social en estos aspectos. Ello será signo de una sociedad rica e inquieta intelectualmente.

\section{Notas}

I. Plan General de Bienes Culturales de Andalucía. 1996-2000. Documento de Avance. Año 1997. Consejería de Cultura : Sevilla, 1997.

2. Crecimiento, competitividad y empleo. Retos y pistas para entrar en el siglo XXI, 1994

3. CLAVIJO PROVENCIO, RAMÓN La Biblioteca Municipal de Jerez de la Frontera, 112 años de historia : con su primer catálogo de sus libros reservados [s. I.] : Consejo Superior de Investigaciones Científicas, Centro de Estudios Históricos Jerezanos, 1986.

4. GONZÁLEZ GONZÁLEZ, FRANCISCO JOSÉ Catálogo de las obras antiguas de autores españoles San Fernando (Cádiz): Instituto y Observatorio de Marina, 1986.

5. MARTÍNEZ LÓPEZ, ROSARIO La biblioteca de la Real Academia Provincial de Bellas Artes de Cádiz Cádiz: Diputación provincial, 2001.

6. Gestido del Olmo, Rosario "Libros relativos a América en la Biblioteca del antiguo Real Colegio de Cirugía de Cádiz" En Hispanoamérica y las Academias de Medicina Españolas. - Cádiz: Real Academia de Medicina, 1992.

7. http://biblioteca.uca.es/biblioteca.htm

8. http://www.sba.junta-andalucia.es/

9. Creado por decisión soberana de Jaime I| de Aragón, en I 3 I8.

10. Inspección General de Archivos: Censo Guía de archivos españoles. Volumen I Álava-Jaén. Madrid: Ministerio de Educación y Ciencia. Dirección General de Archivos y Bibliotecas L.L. 1972

1।. En el Archivo de la Diputación de Cádiz aparece una serie denominada Inventarios de Archivos Municipales (I8651976). En ella se pueden encontrar relación de documentos o "inventarios" que se realizaban en los distintos municipios de la provincia y que eran solicitados por la Administración del Estado, encargándose la Diputación de recopilar esa información. Por otra parte, desde los años treinta, la Diputación provincial viene cumplimentando estadísticas relativas al archivo y a su uso. Puede ser un buen material de trabajo para conocer como ha evolucionado el estado de conservación de las fuentes documentales y realizar una comparativa entre el ayer y el hoy de los fondos documentales locales.

12. Se llevaron a cabo destrucciones cruentas por motivos políticos, sindicales, sociales (Alcalá del Valle, Sanlúcar, Grazalema, Vejer, como más significativos, aunque hubo otras muchas en la provincia como podemos contemplar en los datos aportados más adelante sobre los archivos municipales y sus fechas extremas), o fortuitas, así como eliminaciones programadas, como es el caso de la Diputación de Cádiz, singularmente catastrófico y con la supervisión y beneplácito casi impasible del archivero, y con criterios que no se sostienen hoy. La escasez de pasta de papel y la necesidad de reciclar el papel inservible, fueron utilizados como parámetros justificativos, bajo los cuales se cometieron impunes sacas de documentos, que en este caso de la Diputación se hizo bajo el paraguas legal y con luz y taquígrafos, destruyéndose, según los expedientes de expurgos, desde 1917 hasta 1960 la friolera de 39248 kgs. de papel que sepamos (Cuentas de Propios y Pósitos; Expedientes de Policía Urbana; Expedientes de Beneficencia; Expedientes de Quin- tas; Expedientes de Establecimientos Penales; Expedientes de Intervención y Depositaría; Expedientes Electorales; Expedientes del Hospicio Provincial; Expedientes del Hospital Mora, etc, con valores aproximados podríamos señalar que se han destruido cerca de $1 \mathrm{~km}$ de documentos), y detrás de los etcéteras se escondían anónimas destrucciones con la "finalidad pretendida de descongestionar el local del Archivo"

13. VÁZQUEZ DE PARGA, Margarita: "La Base de datos archivísticos e históricos. Hacia el sistema nacional de información de archivos" En: I Jornadas Españolas de Documentación Automatizada, Madrid: 1984, pp. 849-857

14. http://www.mcu.es/lab/archivos/index.htm|

15. Con respecto a los archivos públicos es más recomendable que contrastemos la información con la que aporta el Censo Andaluz de Archivos -más fiable- o la Guía del Archivo Histórico Provincial, que al ser un centro que actúa como archivo intermedio e histórico tanto de la administración central como autonómica aporta una mayor calidad en la información.

16. Estos archivos han sido tradicionalmente la principal fuente de información para los investigadores, ver comentario y análisis más adelante en el apartado dedicado al Archivo Histórico Provincial de Cádiz.

17. http://www.mde.es/mde/cultura/patrim/archi8.htm El Instituto fue fundado en 1753 como centro de investigación vinculado a la Academia de Guardias Marinas de Cádiz, creada en 1717.

18. http://www.mde.es/mde/cultura/patrim/archi9.htm El Instituto Hidrográfico de la Marina fue creado por una ley de 30 de diciembre de 1943. Tiene documentación desde 1740 fundamentalmente cartográfica.

19. El archivo y la biblioteca del Gobierno Militar de Cádiz ha sido trasladado a la Capitanía General de la Región Militar Sur. Sobre su contenido se puede consultar la comunicación presentada a las VI Jornadas Nacionales de Historia Militar Cátedra General Castaños, año 1996, por Ma GLORIA CANO RÉVORA E INMACULADA CANO RÉVORA " LOS fondos documentales del Cuerpo de Ingenieros en Cádiz: La Biblioteca y el Archivo de su jefatura Logística Territorial". En relación a la biblioteca ver MARTÍNEZ LÓPEZ, ROSARIO; MEDINA BOZANO, MANUEL J:; GALVÁN MARTÍNEZ, Ma JOSÉ La colección bibliográfica de la biblioteca del Real Cuerpo de Ingenieros del Exercito : (S.XVI-S.XIX) Cádiz : Jefatura Logística Territorial, 1995 y CANO REVORA, INMACULADA La colección bibliográfica del gobierno militar de Cádiz Cádiz : Jefatura Logística Territorial, 1998

20. http://www.dipucadiz. Página en donde, entre otros, se pueden consultar los inventarios de los archivos municipales de la provincia de Cádiz.

21. Sin duda otra fuente esencial y tradicional en el campo de la investigación histórica. Podemos decir que hay dos centros principales que son los archivos diocesanos de Cádiz y Jerez -éste tiene incluso centralizados los fondos de archivos parroquiales de su demarcación anteriores a 1900-, y luego todos los parroquiales con disparidad de situaciones. En líneas generales están bien organizados por tener series muy claras y la antigüedad de los fondos es diversa. 
22. La ley $3 / 1984$ de 9 de enero de archivos de Andalucía (BOJA $n^{\circ} 4$, de 10 de enero y corrección de errores $B O J A n^{\circ} \mid 1$, de 28 de enero) establecía en su Título III art. 17 establecía la elaboración del Censo de Archivos Andaluces.

23. HEREDIA HERRERA, ANTONIA (dirección y coordinación) Censo del Sistema Andaluz de Archivos, Sevilla: Empresa de Gestión de Programas Culturales. Consejería de Cultura, 1997.

24. ibídem, p. 9

25. HEREDIA HERRERA, Antonia: "Aproximación al patrimonio documental: El Censo del Sistema Andaluz de Archivos" En : PH Boletín del Instituto Andaluz del Patrimonio Histórico, $\mathrm{n}^{\circ} 19$ (1997), pp. I47-150

26. Consultar la página www.aga.junta-andalucía.es

27. HEREDIA HERRERA, A. y RAVINA MARTíN, M. Bibara, bibliografía archivística andaluza (1978-2000), Sevilla: Consejería de Cultura, 2000. Ver también de la misma autora "BÍBARA: El Patrimonio documental más cerca" En: PH Boletín del Instituto Andaluz del Patrimonio Histórico, $n^{\circ} 32$, septiembre 2000, pp.2।0-2|4. Puede consultarse en la página web del Archivo General de Andalucía.

28. DIRECTORIO DE ARCHIVOS DEL SISTEMA ANDALUZ. Sevilla: Consejería de Cultura. Archivo General de Andalucía, 2000

29. RAVINA MARTíN, MANUEL Guía del Archivo Histórico Provincial de Cádiz, Cádiz: Consejería de Cultura, 1999. Col. Instrumentos de descripción, $n^{\circ}$ 2. En ella podemos encontrar desde la historia del archivo, su cuadro de clasificación, la descripción somera de fondos, con la correspondiente e interesante historia del organismo productor de la documentación, y una amplia bibliografía sobre el edificio y sobre trabajos realizados con fondos del archivo, a modo de guía de investigadores. Podemos decir que es un modelo de Guía de archivo con varios fondos bien confeccionada, aunque no se haya realizado bajo las ya exigibles instrucciones de la norma internacional de descripción de archivos ISAD (G). Imprescindible para conocer el patrimonio documental gaditano, y necesaria para cualquier investigador.

30. ANTÓN SOLÉ, PABLO Catálogo de la sección "Gibraltar" del Archivo Histórico Diocesano de Cádiz : 1518-1806. Cádiz : Instituto de Estudios Gaditanos, Diputación Provincial, 1979. Ver también Rodriguez, María del Carmen "El archivo del Convento de Regina Coeli de Sanlucar de Barrameda (Cádiz)" [Resumen de la comunicación presentada al XIII congreso de profesores-investigadores Hespérides, Los archivos andaluces, Osuna y su comarca, 19-21 Septiembre 1996].

31. Ver Guía de los Archivos y las Bibliotecas de la Iglesia en España, publicada por la Asociación Española de Archiveros Eclesiásticos en 1985.

32. Palacio y Archivo Ducal de Medina Sidonia Sanlúcar de Barrameda (Cádiz) : UNED, [1999] I h. pleg. [6] p. Y El Archivo Ducal de Medina Sidonia : normas de uso / Universidad Nacional de Educación a Distancia.

33. RD 1075/1981, de 24 de abril; D.37/1981, de 13 de julio; D $70 / 198$ I de 30 de noviembre; RD 864/1984, de29 de febrero, o D. 180/1984, de 19 de junio.

34. Ley I //1987, de 26 de diciembre, reguladora de las relaciones entre la Comunidad Autónoma de Andalucía y las Diputaciones Provinciales de su territorio (BOJA n ${ }^{\circ}$ 108, de 30 de diciembre).

35. Ley 7/1985 Reguladora de las Bases del Régimen Local (BOE 3 de abril de 1985).

36. Ver RAVINA MARTÍN, M. "Fuentes Documentales sobre Patrimonio Histórico en los Archivos Históricos Provinciales: el ejemplo de Cádiz" En: PH Boletín del Instituto Andaluz del Patrimonio Histórico, no 32, septiembre 2000, pp.215-219. Podemos encontrar "breves pinceladas de los AHP y la información de primera mano que en sus diferentes secciones se contienen sobre el patrimonio histórico".

37. Ver CAYETANO MARTÍN, Ma DEL CARMEN "La documentación de la administración local en la Edad Moderna" En El patrimonio documental: fuentes documentales y archivos Cuenca: Ediciones de la Universidad de Castilla La Mancha, 1999, pp. 93-1 I5; y también en esas mismas Jornadas RODRÍGUEZ CLAVEL, José Ramón "La documentación de la administración Contemporánea", pp. 239-269. Y PINO REBOLLEDO, F. Tipología de los documentos municipales (siglos XII-XVII) Valladolid: Asociación para la defensa y conservación de los archivos, 1991. Y SECO CAMPOS, ISABEL "Tipología Documental administrativa en el Municipio contemporáneo" En Los Archivos de la Administración Local Toledo: ANABAD Castilla LA Mancha, 1994, p. 93-154.

38. SIMÓ RODRÍGUEZ, MANUEL "El Archivo de la Diputación de Cádiz" En Tria n² 2 (1995), pp. I | I- 122.

39. "Archivos Gaditanos. Archivo Municipal de Cádiz" En Boletín Bibliográfico de Historia, nº 6 (1987), pp. 5-12.

40. EXPÓSITO HERRERA, ROSA, SUÁREZ ÁLVAREZ, GUSTAVO, y MELÉNDEZ BUTRÓN, MANUEL Inventario del Archivo Municipal de Chiclana de la Frontera Cádiz: Diputación Provincial, 1993. Colección Archivos.

41. Existe diferente bibliografía sobre el archivo, consultar Bíbara. En todo caso destacamos El Archivo Municipal de Jerez, Jerez: Ayuntamiento, 1990; ORELLANA GONZÁLEZ, CRISTÓBAL. Índice de las "Memorandas" del Archivo Municipal de Jerez de la Frontera. Jerez de la Frontera: Ayuntamiento, 1991.

42. Existe diferente bibliografía sobre el archivo y una Guía manuscrita, Entre otros se puede destacar BUHIGAS CABRERA, JOSÉ IGNACIO "La sección de "papeles antiguos" del Archivo Municipal de El Puerto de Santa María" En Revista de Archivos y Bibliotecas de Andalucía, n I (1986), pp. I3-19.

43. RUANO FERNÁNDEZ, F. Y BASADRE GONZÁLEZ, P. Documentos del Archivo Municipal de Puerto Real, siglo XIX [catálogo de exposición, con catálogo de documentos]. Puerto Real, 1992.

44. LÓPEZ GARRIDO, J.L. Inventario de Fondos del Archivo Municipal de San Fernando (1677-1984), San Fernando. Ayuntamiento, 1989.

45. RODRÍGUEZ CABAÑAS, A.L. Guía del Archivo Municipal de Sanlúcar de Barrameda. Sanlúcar de Barrameda: Ayuntamiento, 1988.

46. CRIADO ATALAYA, F.J. "La ordenación y catalogación de fondos del Archivo Municipal de Tarifa". En Almoraima, n 15 (1996), pp. 405-4I4.

47. Se está finalizando la organización del archivo y el Inventario verá la luz en el año 2002.

48. RUANO FERNÁNDEZ, Francisca, y MARTíN MILA, Victoria (dirección: RODRÍGUEZ CABAÑAS, ANTONIO L.) Inventario del Archivo Municipal de Alcalá de los Gazules. Cádiz: Diputación Provincial, 1999. Colección Archivos.

49. En prensa.

50. RODRÍGUEZ CABAÑAS, A.L., Y SUÁREZ ÁLVAREZ, GUSTAVO Inventario del Archivo Municipal de Chipiona Cádiz: Diputación Provincial, 1992. Colección Archivos.

5।. GOMAR TINOCO, CARMEN, Y GARCÍA DE PAREDES, PAZ (dirección: RODRÍGUEZ CABAÑAS, Antonio L.) Inventario del Archivo Municipal de Espera. Cádiz: Diputación Provincial, 1999. Colección Archivos.

52. MARTÍN MILA, VICTORIA, Y RUANO FERNÁNDEZ, FRANCISCA, Inventario del Archivo Municipal de Medina Sidonia. Cádiz: Diputación Provincial, 1992. Colección Archivos.

53. En prensa

54. En fase de organización, tiene un inventario cronológico antiguo que abarca la documentación de 1556 a 1899.

55. El Fondo del Archivo Municipal se encuentra en muy mal estado y disperso, sus fechas extremas son 1817/1995; también contiene los fondos de protocolos notariales del distrito notarial de Algeciras con fechas extremas de 1557//894.

56. DE VICENTE LARA, J.I. y OJEDA GALLARDO, M.M. "Los Fondos Documentales del Archivo Municipal de Jimena de la Frontera (I810-1985)" En Almoraima, n 15 (1996), pp. 333-345.

57. TORNAY DE COZAR, F. "El Archivo Histórico Municipal de La Línea de la Concepción" En Almoraima, n I5 (1996),pp. 357-366. http://www.lalinea.com/archivo.htm. 